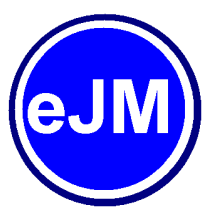

\title{
How do newly-qualified doctors perceive empathy in medical training and practice?
}

\author{
Steven Agius ${ }^{1}$, Jeremy Brown ${ }^{2}$, Emily Stratta ${ }^{3}$, Jacky Hayden ${ }^{4}$, \\ Paul Baker ${ }^{1}$
}

\author{
${ }^{1}$ Health Education \\ England (North West), \\ Manchester, UK, \\ 2Department of Clinical \\ Education, Edge Hill \\ University, Ormskirk, UK, \\ ${ }^{3}$ Department of Obstetrics \\ and Gynaecology, Frimley \\ Health NHS Foundation \\ Trust, UK, ${ }^{4}$ President of \\ the Academy of Medical \\ Educators, Cardiff, UK \\ Address for correspondence: \\ Dr. Steven Agius, Health \\ Education England (North \\ West), 3 Piccadilly Place, \\ Manchester M13BN, \\ UK. Tel.: 01616257668. \\ Fax: 01616257510. \\ E-mail: steven.agius@hee. \\ nhs.uk \\ Received: January 11, 2017 \\ Accepted: March 10, 2017 \\ Published: June 12, 2017
}

\begin{abstract}
Objective: Evidence exists of an apparent decline in empathy during medical training which may be detrimental to patient care. This qualitative study explores the reflections of a group of newly-qualified foundation doctors with regard to empathy in medical training and practice. Methods: Doctors in a UK Foundation Training Programme were invited to reflect on the subject of empathy in medical training and practice. Researchers obtained consent to access their anonymous reflective statements and analyze for recurring themes using framework analysis. Results: Coding of 65 trainees' reflective statements resulted in identification of two thematic categories: (i) preparedness for empathic patient care and (ii) therapeutic effect of empathy. Conclusions: Trainees are aware of the value of empathy as a therapeutic tool. Many use it instinctively but not systematically. Clinical pressures can impact negatively on empathic dealings with patients and relatives. Targeted educational interventions and positive role modeling may assist foundation doctors enhance their skills in patient-centered care.
\end{abstract}

KEY WORDS: Communication skills, empathy, physician, profession, professionalism/ethics, reflective practice

\section{INTRODUCTION}

In recent years, there has been considerable debate about an apparent decline in empathy during medical training. There is some evidence, particularly from the USA, that medical students' empathy scores diminish upon entering clinical rotations and that empathy levels reduce during US internships [1,2]. Although the basis of such conclusions has been questioned in some quarters [3], there remain concerns that "ethical erosion" among health professionals may have a detrimental effect on patient care [4]. In the UK, publication of the report of the Mid Staffordshire NHS Foundation Trust Public Inquiry highlighted the consequences for patient care when a lack of staff empathy prevails within a clinical environment [5].

Medical schools routinely teach empathy as part of communication skills training. The transition from medical school to medical practice, with all the pressures and responsibilities that entail, can be challenging [6]. The importance of empathy in medical practice is emphasized repeatedly in the UK Foundation curriculum (covering the first 2 years of training following graduation from medical school), where trainees are informed that "they must learn how to empathize with patients' conditions," "act with empathy, honesty, and sensitivity and in a non-confrontational manner," and "recognize that patients may have unspoken concerns and communicate in an empathic manner to elicit and address these [7]."

Research into empathy in medicine has been dominated by quantitative approaches, largely utilizing self-assessment questionnaires [8]. A small number of studies have adopted qualitative methods to explore the subject of empathy in greater depth. While the majority have focused on medical students, some also deal with doctors in training [9]. In this study, we have attempted to augment the limited qualitative evidence base with a study that explores the perceptions of newly-qualified UK 
Foundation doctors with regard to empathy through analyzing reflective narratives on the subject. The overarching aim was to explore the UK Foundation trainees' perceptions of empathy in medical training and practice.

\section{METHODS}

All foundation doctors in the UK have access to an electronic portfolio (e-portfolio) which they can use to record information relating to their training, including reflective statements, supervised learning events, personal and professional development plans, assessments, and educational meetings. Doctors in the first year of a foundation (FYl) training program in a region of England were invited to reflect on the subject of empathy in medical training and practice, using their e-portfolio to record a reflective statement. The e-portfolio was used so that the reflective statements would serve an enduring educational purpose for the individual doctors as well as providing qualitative data for the research team. The research team obtained written consent from trainees to access their reflective statements from the e-portfolio administrator who was responsible for ensuring that all written material was anonymous.

Reflective statements were analyzed for recurring discourses and themes using a thematic framework analysis. Silverman has proposed that an advantage of analyzing existing text is that it is potentially more reliable than data already collected and filtered by researchers trying to make sense of audio recordings or field notes [10]. The research team acted as coanalysts and a coding framework was devised as a result of their deliberations. The team consists of clinicians and non-clinicians with expertise in postgraduate medical education research. This construction of codes and thematic categories was done by the co-analysts working independently and deliberating together on interpretations until agreement was reached.

The quality of the findings is highly dependent on the rigor of the data collection and subsequent analysis and interpretation. We attempted to achieve rigor using established techniques to ensure credibility, transferability, dependability, and confirmability [11]. Inter-rater reliability ensured that multiple coders were involved in identifying areas of agreement to ensure consistency and to minimize any potential for bias in interpretation. There were very limited disagreements about coding definitions and all were successfully resolved. The research team engaged in constant comparison, involving checking the consistency and accuracy of interpretation and especially the application of codes, as well as careful consideration of negative cases. Records of all data analysis activities were maintained so that genesis of interpretation could be tracked, ensuring auditability.

We secured permission to undertake this research from a regional Health Education England (HEE) Research Governance Committee which reviews proposed educationrelated studies for scientific quality and ethical integrity. Separate Ethical Approval from the NHS and Health Research Authority was not required.

\section{RESULTS}

A cohort of FYl trainees in a regional foundation school was invited to record qualitative reflections on the subject of empathy in their e-portfolio.

Thematic framework analysis of reflective statements was conducted until data saturation was reached: 65 statements were analyzed in total. This process generated a series of codes [Table 1] which were subsequently grouped into two thematic categories. Each of these is set out in the following pages, with illustrative data extracts.

\section{Preparedness for Empathic Patient Care}

The majority of respondents appreciated the value of educational interventions to develop and refine their empathy skills, particularly during foundation training (FT). For many of them, completing a psychometric test was perceived as a useful trigger for self-reflection on the subject of empathy and how it was manifested in their day-to-day lives as clinicians:

Completing this questionnaire surprised me. It made me realize that while I give intellectual assent to empathy, I do not actually apply it in my practice as much as I thought (FT16).

A minority of respondents stated, however, that they were upset by the apparent need to assess doctors for empathy, believing that the vast majority of people who entered healthcare professions did so in part because they were naturally empathic. Nurturing empathy by educational intervention was also thought to be unnecessary by some trainees because it was "a prerequisite for the job."

Most trainees in our sample had learned about the theoretical value of empathy in patient care as part of communication skills training while at medical school. For many newly-qualified doctors, however, the impact of their verbal and behavioral interactions with patients on the latter's well-being only became fully apparent once they were qualified and experienced it for themselves. There was a degree of dissonance between the theory and practice of empathy among respondents. Trainees knew what was expected of them - "What is right and how to act appropriately with patients" - but could struggle putting it into practice with every patient encounter:

Table 1: Perceptions of empathy in medical training and practice

\begin{tabular}{ll}
\hline Thematic category & \\
\hline $\begin{array}{l}\text { Preparedness for } \\
\text { empathic patient care }\end{array}$ & Therapeutic effect of empathy \\
\hline Constituent codes & \\
Nature versus nurture & Patient/doctor benefits \\
Theory into practice & Cognitive versus affective \\
Spiral curriculum & Risk factors \\
Role modeling & Patient characteristics/behaviors \\
\hline
\end{tabular}


Empathy has always been seen as quite important theoretically as far as the medical profession and clinical aspects of management are concerned. However, in practice, being a foundation doctor and being pressed for time make it a bit difficult to effectively implement it each and every time (FT7).

There was recognition that failings in empathic practice could have negative implications for clinical outcomes:

I think that I probably use empathy skills less than I think I do and lose a lot of rapport and patient confidence due to this (FT62).

Most of the bad interactions have been when I could not empathize with the patient or their family (FT19).

The majority of trainees claimed to use empathy instinctively but often unknowingly while acknowledging that they did not always use it systematically. This was perceived as a potential failing in certain clinical situations, including on call, when a number of trainees reflected on their need to be as empathic as they would be with "normal day patients" - a challenge which previous educational interventions had not apparently addressed adequately.

There was a perceived absence of empathy skills training in the foundation curriculum. We identified a desire for its presence in the spiral curriculum, with formal educational sessions on this subject, revisiting the theoretical perspectives first encountered in medical school in an applied setting. A common theme in the dataset was that certain specialties, because of their very nature, readily presented opportunities for honing empathy skills. Working in medicine with chronic patients, for example, or in care of the elderly where the majority of patients had multiple comorbidities, or in palliative care, was seen as particularly valuable for experiential learning. In terms of an educational intervention, however, trainees who had recently undertaken psychiatry placements stated that this experience had made them significantly more attuned to the important role of empathy as a therapeutic tool.

Many trainees reflected upon the informal yet powerful impact on their empathy skills of positive role modeling in the workplace, both from senior medical colleagues and other members of the clinical team.

As physicians, it may be very easy to forget that the patient is in a very vulnerable state, not only from a medical standpoint but also from an emotional one. I have seen certain doctors forget this and have seen how detrimental this can be to the doctor-patient relationship and the patient's care as a whole. I have also seen other fantastic doctors (and other healthcare professionals) use empathy as a means to build their professional relationship with the patient, allowing them to gain a trust that builds a framework for better healthcare (FT32).

\section{Therapeutic Effect of Empathy}

Many trainees reflected upon the value of empathy in medical practice as a therapeutic tool. Empathy was perceived as therapeutic for doctors as well as patients, particularly in the early years of their training when they were building up their applied knowledge and skills for a working lifetime of clinical practice. While not all trainees had previously considered empathy to be a management tool in its own right, the majority reflected on the value of adopting a more consistent approach for using empathic strategies to improve clinical outcomes:

Empathy has a therapeutic role - I know that being seen by a doctor-and being taken seriously by them - has a therapeutic effect in and of itself - I already practice this, and the art of reassurance, when asked to see patients (FT3).

A significant number of respondents highlighted aspects of cognitive and affective empathy without specifically referring to those terms. The importance of effective communication with patients and their relatives was seen as paramount, particularly with regard to regular engagement and updating about treatment plans. The consensus appeared to be that clinicians should avoid being glib about understanding patients' experiences as this was not always possible. Although an experience might be imagined, the focus in such circumstances should be on treating people with compassion, dignity, and respect as anyone would wish to be treated in a similar situation.

Foundation trainees in our sample perceived the nexus of patient/family/doctor as lying at the heart of empathic medicine, including being sensitive to emotions; picking up non-verbal cues; listening to narratives; and engaging patients and their families in clinical decision-making while striving to maintain a degree of professional detachment. Some trainees explicitly stated that empathy should not be allowed to unduly influence treatment plans:

I sometimes feel that patients' beliefs and desires can cloud my clinical judgment. I will always aim to counterbalance my empathy with sound clinical judgment (FT22).

I need to try and detach myself a bit more from my patients and their families because, while I feel it is important to show empathy, one has to remain neutral and professional to deliver the best care (FT28).

Respondents reflected that it was often far from easy for doctors to be always empathic when the pressures of a busy clinical job preclude them from spending lengthy periods of time getting to know individual patients and hearing about their concerns:

There are times when I am tired, stressed, when I feel I begin to look at my patients like numbers and have to actively remind myself that they are humans and to put myself in their position (FT40). 
Trainees also demonstrated a keen awareness of the risk factors that can potentially decrease a doctor's empathy, including workload, stress, and fatigue:

There were times when I was overwhelmed with the number of bleeps and all sorts of odd jobs, all over the hospital, and the elderly, lonely patients wanted to chat with me, but I just could not afford to stay for long and listen to all their conversations (FT15).

I think it is a problem of understaffing resulting in a constantly stressed and fatigued workforce which has developed a culture of numbness to patients' needs (FT53).

Trainees in our study also revealed that patient characteristics and behaviors can trigger different empathic responses. A number of respondents reflected that it was easier to show empathy to some patients than others. Some trainees found it challenging to empathize with "difficult" patients but recognized this as a communication issue which they needed to address:

Employing empathy may help improve working relations with antagonistic patients - My current placement has several patients who are sometimes antagonistic toward the medical staff - I am consequently wary around them (in case they complain or become obstructive) and need to restrain myself from appearing hostile - People rarely behave obstructively without some provocation. I may find it easier to deal with these patients if I am empathetic to their situations, which are often quite unfortunate (FT16).

Patients are very different and I find it easier to relate to some patients more than others - e.g. aggressive/manipulative patients who may have substance misuse disorders (such as alcohol dependence). In general, I do make efforts to empathize with patients, but this can occasionally be negatively affected by time constraints (FT31).

\section{DISCUSSION}

There is an argument that clinical environments where doctors learn their craft may have a detrimental impact upon empathy levels [12]. There is certainly a weight of published evidence which suggests erosion of empathy can occur during the medical training process [4]. If empathic patient care does indeed decline during clinical training, then there is a strong case for augmenting postgraduate curricula so that foundation doctors can revisit the theory and apply their enhanced knowledge and skills in practice. Even if the case for ethical erosion is not well founded, as some author's claim [3], our pragmatic and interpretive investigation of FTs' written accounts suggests that trainees would value the opportunity to refine their empathic behaviors through effective educational interventions and positive role modeling.

Evidence suggests that empathy from medical professionals has a positive impact on patients. One study found that patient-centered communication was correlated with patients' perceptions of finding common ground with their physician, which were associated with better recovery from their discomfort and concern, better emotional health, and fewer diagnostic tests and referrals [13]. Another study found that patientperceived physician empathy significantly influenced patient satisfaction and compliance through the mediating factors of information exchange, perceived expertise, interpersonal trust, and partnership [14].

A key consideration is the type of empathic medicine which doctors should practice on a day-to-day basis for the benefit of patients but also, crucially, to safeguard themselves against compassion fatigue, vicarious trauma, and emotional exhaustion [15]. Empathy is generally regarded as a cognitive attribute rather than a personality trait although certain traits may make it easier for some people to experience and demonstrate empathy. The distinction between affective and cognitive empathy is particularly important when it comes to the doctor/patient relationship [16]. Affective empathy is an automatic response to another person's emotional state, including their pain or distress. An excess of affective empathy can be detrimental to the psychological well-being of health professionals: A potential cause of stress and burnout. The capacity to remain detached, but not remote, is crucial in enabling medical practitioners to make objective safe, clinical judgments.

Cognitive empathy is the ability to recognize and understand another person's perspective or mental state, rather than an emotional response. It has been suggested that it is possible to learn the cognitive components of empathy even in the absence of the affective component [17]. Medical practice is intense and often highly pressured. It may, on occasion, cause doctors to feel that there is a tension between empathy for the patient and the drive for efficiency in clinical practice. To avoid this duality and ensure a more systemic approach to empathic patient care, our research suggests that doctors in the early years of postgraduate training may benefit from positive role modeling and targeted educational interventions on the subject [18].

In the international medical education literature, there are numerous examples of empathic behaviors having been successfully taught to doctors. Targeted physician communication training has been shown to make a significant difference in physician empathic expression during patient interactions demonstrated by both outside observer measures of global ratings and hierarchical ratings of physician empathic behavior [19]. A randomized controlled trial of an empathy training intervention grounded in neuroscience found that physician empathy as rated by patients significantly improved [20]. Computer-based training programs have been shown to improve doctors' empathic response to patients' expressions of negative emotions [21]. Interventions grounded in the humanities have proved to be efficacious, such as programs in narrative medicine which emphasize the importance of understanding patients' life stories in providing compassionate care [22]. Cultivating empathy for the mentally ill may be done using simulated auditory hallucinations [23], 
while Balint groups might be used to enhance empathy and psychological skills [24]. Such studies suggest that empathy can be reinforced and strengthened with targeted training. Training programs which allow for continuity of care, enabling a continuous therapeutic relationship with a clinician and consistency of clinical management, can also enhance empathic skills [25].

There are a number of limitations with our study. The research team conducted the research in an attempt to obtain rich qualitative data from participants about an under-researched subject. As with much qualitative work, the sample was necessarily small: Data were gathered from doctors in a single foundation school and so are not representative of FTs' views across the UK which has inevitable limitations for generalizability in the quantitative sense. The 65 trainees who voluntarily provided reflective narratives were a self-selected group which may have introduced a degree of bias to the dataset. Various factors may have influenced an individual's reflections on the subject of empathy at the time of data collection, including their personal context in terms of current clinical specialty, workload, and resilience levels. It should also be noted that social desirability may have led participants to self-censor their actual views. We attempted to limit this possibility by placing emphasis on the assured anonymity of participants.

The majority of trainees are aware of the value of empathy as a therapeutic tool. Many use it instinctively but realize that they do not always use it systematically. The pressures of the clinical environment can impact negatively upon empathic dealings with patients and relatives. Some trainees find it challenging to empathize with "difficult" patients but recognize this as a communication issue which they will need to address. Targeted educational interventions and positive role modeling during FT may assist doctors enhance their skills in empathic patient care.

\section{ACKNOWLEDGMENTS}

We gratefully acknowledge HEE for funding the research and thank all the foundation doctors who participated in this study.

\section{REFERENCES}

1. Hojat M, Vergare MJ, Maxwell K, Brainard G, Herrine SK, Isenberg GA, et al. The devil is in the third year: A longitudinal study of erosion of empathy in medical school. Acad Med 2009;84:1182-91.

2. Bellini LM, Shea JA. Mood change and empathy decline persist during three years of internal medicine training. Acad Med 2005;80:164-7.

3. Colliver JA, Conlee MJ, Verhulst SJ, Dorsey JK. Reports of the decline of empathy during medical education are greatly exaggerated: A reexamination of the research. Acad Med 2010;85:588-93.

4. Neumann M, Edelhäuser F, Tauschel D, Fischer MR, Wirtz M, Woopen $\mathrm{C}$, et al. Empathy decline and its reasons: A systematic review of studies with medical students and residents. Acad Med 2011;86:996-1009.
5. Francis R. Report of the Mid-Staffordshire NHS Foundation Trust Public Inquiry. London: The Stationery Office; 2013.

6. Brennan N, Corrigan O, Allard J, Archer J, Barnes R, Bleakley A, et al. The transition from medical student to junior doctor: Today's experiences of Tomorrow's Doctors. Med Educ 2010;44:449-58.

7. The UK Foundation Programme Curriculum. In: Academy of Medical Royal Colleges. Available from: http://www.aomrc. org.uk/publications/reports-guidance/foundation-programmecurriculum-2016-2/. [Last accessed on 2016 Dec 02].

8. Pedersen R. Empirical research on empathy in medicine-A critical review. Patient Educ Couns 2009;76:307-22.

9. Aomatsu M, Otani T, Tanaka A, Ban N, van Dalen J. Medical students' and residents' conceptual structure of empathy: A qualitative study. Educ Health (Abingdon) 2013;26:4-8.

10. Silverman D. Interpreting Qualitative Data. $4^{\text {th }}$ ed. London: Sage; 2011.

11. Bryman A. Social Research Methods. Oxford: Oxford University Press; 2008.

12. Haque OS, Waytz A. Dehumanization in medicine: Causes, solutions, and functions. Perspect Psychol Sci 2012;7:176-86.

13. Stewart M, Brown JB, Donner A, McWhinney IR, Oates J, Weston WW, et al. The impact of patient-centered care on outcomes. J Fam Pract 2000;49:796-804.

14. Kim SS, Kaplowitz S, Johnston MV. The effects of physician empathy on patient satisfaction and compliance. Eval Health Prof 2004;27:237-51.

15. McCann IL, Pearlman LA. Vicarious traumatization: A contextual model for understanding the effects of trauma on helpers. J Trauma Stress 1990:3:131-49.

16. Hojat M. Empathy in Patient Care: Antecedents, Development, Measurement and Outcomes. New York: Springer; 2007.

17. Morse JM, Anderson G, Bottorff JL, Yonge O, O'Brien B, Solberg SM, et al. Exploring empathy: A conceptual fit for nursing practice? Image J Nurs Sch 1992;24:273-80.

18. Kelm Z, Womer J, Walter JK, Feudtner C. Interventions to cultivate physician empathy: A systematic review. BMC Med Educ 2014;14:219.

19. Bonvicini KA, Perlin MJ, Bylund CL, Carroll G, Rouse RA, Goldstein MG. Impact of communication training on physician expression of empathy in patient encounters. Patient Educ Couns 2009;75:3-10.

20. Riess H, Kelley JM, Phillips M. Empathy training for resident physicians: A randomized controlled trial of a neuroscience-informed curriculum. J Gen Intern Med 2012;27:1280-6.

21. Tulsky JA, Arnold RM, Alexander SC, Olsen MK, Jeffreys AS, Rodriguez KL, etal. Enhancing communication between oncologists and patients with a computer-based training program: A randomized controlled trial. Ann Intern Med 2011;155:593-601.

22. Charon R. Narrative Medicine: Honouring the Stories of Illness. New York: Oxford University Press; 2006.

23. Bunn W, Terpstra J. Cultivating empathy for the mentally ill using simulated auditory hallucinations. Acad Psychiatry 2009;33:457-60.

24. Ghetti C, Chang J, Gosman G. Burnout, psychological skills, and empathy: Balint training in obstetrics and gynecology residents. J Grad Med Educ 2009;1:231-5.

25. Gray DP, Evans P, Sweeney K, Lings P, Seamark D, Seamark C, et al. Towards a theory of continuity of care. J R Soc Med 2003;96:160-6.

(C) EJManager. This is an open access article licensed under the terms of the Creative Commons Attribution Non-Commercial License (http:// creativecommons.org/licenses/by-nc/3.0/) which permits unrestricted, noncommercial use, distribution and reproduction in any medium, provided the work is properly cited.

Source of Support: Nil, Conflict of Interest: None declared. 